\title{
Population Ageing and Capital Accumulation: A Simple OLG Model with PAYGO Pensions
}

\author{
Joachim Thøgersen \\ Oslo and Akershus University College of Applied Sciences, Oslo, Norway \\ Email: joachim.thogersen@hioa.no
}

Received 11 February 2015; accepted 18 March 2015; published 25 March 2015

Copyright (C) 2015 by author and Scientific Research Publishing Inc.

This work is licensed under the Creative Commons Attribution International License (CC BY). http://creativecommons.org/licenses/by/4.0/

c) (i) Open Access

\begin{abstract}
Population in developed countries has dramatically aged in recent years. At the same time, most of these countries finance their old-age public pension benefits on a pay-as-you-go (PAYGO) basis. Such a pension scheme combined with an ageing population, represent a financial challenge for the governmental budgets. Accordingly, several studies have been done on the effects of population ageing. In the present paper, the purpose is to study how population ageing will affect capital accumulation. A simple OLG model with PAYGO pension is applied. The formulation of the model makes it possible to deduce an explicit expression for this relation. It is shown that an increase in the elderly dependency ratio will increase the long-run capital stock.
\end{abstract}

\section{Keywords}

Overlapping Generations, PAYGo Pensions, Population Ageing and Capital Accumulation

\section{Introduction}

In the vast majority of countries around the world, the demographic structure is expected to change in the coming decades. The demographic change is due to declining fertility rates and higher life expectancies. This demographic transition process results in a general ageing of the population and a reduction in the population growth rate. Some countries are even expected to experience negative growth rates (Börsch-Supan, et al., [1]). Similar tendencies are expected in most economies, though the pace and the timing differ substantially between different regions and countries. Thus, different countries are in different stages of the demographic transition process. Several European and some Asian countries are in the closing stages, while North America is somewhat earlier in the process. However, Latin America is only in the beginning of the transition process, and Africa is still characterized by high fertility rates (United Nations, 2005, [2]).

The ageing process can be illustrated by studying the old-age dependency ratio, as in Table 1. 
Table 1. Old-age dependency ratio: Age 65+/Age 20 - 64 years.

\begin{tabular}{ccccc}
\hline Country & 2000 & 2015 & 2030 & 2045 \\
\hline USA & 20.9 & 24.7 & 36.8 & 39.1 \\
Finland & 24.7 & 35.4 & 47.8 & 48 \\
Germany & 26.2 & 35.3 & 52.1 & 63 \\
Norway & 25.8 & 27.9 & 36.1 & 41.8 \\
Japan & 27.6 & 47.2 & 58.2 & 75.3 \\
\hline
\end{tabular}

Source: United Nations, 2012.

It is clear from this table that all the included countries are characterized by a transition to an older population.

Most of the countries that experience population ageing also mainly rely on pay-as-you-go (PAYGO) pension systems. At the time these systems where implemented, the first old generation did not contribute.

The combination of ageing and PAYGO may cause severe pressure on public finances. The number of contributors decrease, while the number of retirees increase. That implies a smaller tax base, and higher pension liabilities.

Motivated by these issues the current paper explores how population ageing affects capital accumulation, when the social security system is run as a PAYGO pension program.

The literature considering population ageing and macroeconomic implications is vast and characterized by many different approaches. Cutler et al. [3] applies a Ramsey-Cass-Koopmans growth model and studies optimal policy responses to ageing. They conclude that an optimal policy response could be to decrease the national saving rate and increase consumption. This seminal work has been followed by a number of papers. But, instead of the Ramsey-Cass-Koopmans model the majority of the followers employs an OLG model. Most of these contributions adopts a numerical approach and presents simulation experiments. For computable small scale models see Sadahiro and Shimasawa [4] and Attansio and Violante [5]. However, most of the numerical approaches rely on large scale models. Their approach is mainly based on the path-breaking work of Auerbach and Kotlikoff [6].

In contrast to these papers the current one will focus on a simple model structure. This enables more tractable solutions with respect to the underlying mechanisms. Narrowing the literature to theoretical approaches, central contributions are Meijdam and Verbon [7] and Marchand et al. [8]. Marchand et al. studies optimality issues of unfunded pension schemes when fertility changes. Their focus is on welfare implications and whether the introduction of ascending transfers are welfare improving. Meijdam and Verbon explore the effects of ageing on the evolution of public pension schemes. The government is assumed to be a social planner that maximize a social welfare function in order to respond optimally to an ageing shock. Both of these theoretical contributions focus on whether an unfunded pension scheme is optimal in an ageing economy, based on welfare considerations. In the current paper, I will rather take the pension system as given, and consider growth issues when the economy experience higher dependency ratios due to lower fertility rates. The contribution of the paper is thus to study the effect of population ageing on capital accumulation in an analytically tractable set up. Explicit solutions are obtained and the underlying mechanisms explained. Moreover, the formulation of the model makes it possible to do several extensions in order to highlight other aspects of the pension policy debate.

This paper proceeds as follows. Section 2 present the model. In Section 3, the effect of population ageing on capital accumulation is analyzed. Section 4 concludes.

\section{The Model}

Let us consider an overlapping generations economy in the spirit of Diamond [9]. It is assumed that the economy produces one physical good that can be either consumed or saved and thereby generating capital. Time $t$, is discrete and goes from zero to infinity.

\subsection{Demographics}

Each household live for two periods, works in the first period and are retired in the second. Population grows 
exogenously according to:

$$
N_{t}=\left(1+n_{t}\right) N_{t-1},
$$

where the exogenous variable $n_{t} \in(-1, \infty)$ denotes the growth rate of the population. ${ }^{1}$ Notice that the entire population size has a certain growth rate. This simplification is convenient to derive explicit solutions. Population ageing is within this framework interpreted as a permanent reduction in $n_{t}$. The elderly dependency ratio is given by:

$$
\frac{N_{t-1}}{N_{t}}=\frac{1}{1+n_{t}}>0
$$

where a permanent drop in fertility at time $t$ corresponds to an increase in the dependency ratio, i.e. the number of young workers becomes a smaller fraction of total population, relatively to retired individuals in period $t$, $N_{t-1}$. Note that demographic structures over one lifecycle are relatively easy to forecast. Therefore, it is assumed that each individual is endowed with perfect foresight and will adjust their behavior as young if they expect a demographic change when they reach retirement.

\subsection{Households and Firms}

A representative individual born in period $t$, endowed with perfect foresight, maximize a lifetime utility function defined over consumption when young $c_{t}^{y}$, and consumption when old $c_{t+1}^{o}$. The utility function is of the logarithmic Cobb-Douglas form:

$$
U\left(c_{t}^{y}, c_{t+1}^{o}\right)=\gamma \log c_{t}^{y}+\rho \log c_{t+1}^{o}, \quad \text { where } \gamma+\rho=1 .
$$

Young agents in period $t$ inelastically offer one unit of labor at wage $w_{t}$. A part of the wage is paid as a tax to the government to finance the pension system. This contribution is lump-sum and denoted by $\tau_{t}$. The remainder of the wage can either be consumed or saved. Consumption when young is therefore given by $c_{t}^{y}=w_{t}-\tau_{t}-s_{t}$. In the second period of life the representative individual born in period $t$ is retired and consumes the proceedings of first period savings, along with the social security benefits. As savings are used to finance capital in the next period, they earn the interest rate of the next period, $r_{t+1}$. The social security benefit is also lump-sum, and denoted by $\Theta_{t}$. The budget constraint for the second period of life is then $c_{t+1}^{y}=\left(1+r_{t+1}\right) s_{t}+\Theta_{t+1}$. Combining these constraints yields the intertemporal budget constraint for the representative individual:

$$
c_{t}^{y}+\frac{1}{1+r_{t+1}} c_{t+1}^{o}=w_{t}-\tau_{t}+\frac{1}{1+r_{t+1}} \Theta_{t+1}=: W_{t},
$$

where $W_{t}$ denotes lifecycle income. The decision problem for young agents born in period $t$ is to maximize lifetime utility (2) with respect to consumption, subject to the consolidated budget constraint in (3). From this problem the savings function is defined as:

$$
s_{t}:=\underset{c_{t}^{y}, c_{t+1}^{o}}{\arg \max }\left\{U\left(c_{t}^{y}, c_{t+1}^{o}\right) \mid c_{t}^{y}+\left(1+r_{t+1}\right)^{-1} c_{t+1}^{o}=W_{t}\right\} .
$$

Upon the Cobb-Douglas utility function along with the budget constraints in period $t$, the expression for optimal individual savings becomes:

$$
s_{t}=\rho\left(w_{t}-\tau_{t}\right)-\gamma \frac{\Theta_{t+1}}{1+r_{t+1}} .
$$

Savings are thus increasing in net income and the interest rate, while the social security benefit reduces individual savings. By excluding the government and considering a Laissez-Faire economy, all contributions and benefits are set to zero. Hence:

$$
\text { If } \tau_{t}=\Theta_{t}=0 \forall t \Rightarrow s_{t}=\rho w_{t} \forall t,
$$

Which simply gives savings as an increasing function of the wage. The interest rate do not affect optimal savings in this case due to the logarithmic utility function, which yields an intertemporal substitution elasticity

\footnotetext{
${ }^{1}$ Abstracting from mortality, $n_{t}$ also measures the rate of fertility in period $t$.
} 
equal to 1 .

Let us turn to the production side of the economy. There are two input factors, capital $K$, and labor $L$. The depreciation rate of capital is assumed to be zero. Output is given by a the Cobb-Douglas production function $Y_{t}=F\left(K_{t}, L_{t}\right)=K_{t}^{\alpha} L_{t}^{\beta}$, where $\alpha$ and $\beta$ denotes capital share and labor share respectively. It is assumed that:

$$
\alpha>0, \beta>0, \alpha+\beta=1,
$$

where the last assumption imply constant returns to scale. Each young individual supplies one unit of labor, and production per head of the young is thus expressed by:

$$
y_{t}=k_{t}^{\alpha} \text {, where } k_{t}:=K_{t} / L_{t} .
$$

Firms are maximizing profits under perfect competition and their competitive behavior leads to the equalization of factor input prices and marginal products:

$$
\begin{aligned}
& r_{t}=\alpha k_{t}^{-\beta}, \\
& w_{t}=\beta k_{t}^{\alpha} .
\end{aligned}
$$

\subsection{Social Security}

The government enter the economy in a simple way and is not involved in neither consumption nor production activities. In each period $t$, the government collects taxes $\tau_{t}$ from the young workers and provides the old individuals with a pension benefit, in a PAYGO manner. Moreover, the government follows a defined contribution program. Taxes are then exogenous and assumed to be constant over time, i.e. $\tau_{t} \equiv \tau$, and the benefit level is endogenous and adjusts itself appropriately.

With a PAYGO transfer scheme, the budget constraint of the government is given by $\tau_{t} N_{t}=\Theta_{t} N_{t-1}$. Rewriting this budget condition and inserting fixed taxes, yields the following expression for pension payments:

$$
\Theta_{t}=\left(1+n_{t}\right) \tau,
$$

where $n_{t}$ reflects the implicit rate of return of the PAYGO system. As population ageing is interpreted as a decrease in $n_{t}$, the net value of the pension payment will depend on the the demographic structure in the economy.

\subsection{Equilibrium Dynamics}

There are three markets in this economy. Equilibrium in the labor market is given by $L_{t}=N_{t}$. The final good market equilibrium display the resource constraint for the economy as a whole, and states that output can either be used for consumption $C_{t}$, or investments $I_{t}$, i.e. $Y_{t}=C_{t}+I_{t}$.

The equilibrium condition of the capital market equates the supply of capital due to savings, and firms demand for capital. The next period's capital is therefore given as $K_{t+1}=N_{t} s_{t}$. The dynamic behavior of capital per young individual in the economy is thus:

$$
\left(1+n_{t+1}\right) k_{t+1}=s_{t} .
$$

Inserting the savings function (5) and constant taxes into the equilibrium condition in (11), gives the dynamics of capital per worker as:

$$
\left(1+n_{t+1}\right) k_{t+1}=\rho\left(w_{t}-\tau\right)-\gamma \frac{\Theta_{t+1}}{1+r_{t+1}} .
$$

The above expression describes the equilibrium in the capital market. Notice that the first order conditions in (8) and (9), imply that $w_{t}=w\left(k_{t}\right)$ and $r_{t+1}=r\left(k_{t+1}\right)$. Moreover, as the PAYGO program implies that $\Theta_{t}=\Theta\left(n_{t}\right)$, the population growth rate determines the growth in pension benefits, provided that taxes are fixed.

Accordingly, by inserting the first order conditions in (8) and (9), and the government's budget restriction in (10), into Equation (12), one obtains the dynamics of capital intensity as a trajectory $\left\{k_{t}\right\}_{t=0}^{\infty}$ given by an implicit, nonlinear difference equation of the first order: 


$$
\left(1+n_{t+1}\right) k_{t+1}=\rho \beta k_{t}^{\alpha}-\tau\left(\rho+\gamma \frac{1+n_{t+1}}{1+\alpha k_{t+1}^{-\beta}}\right),
$$

where $k_{0}>0$ is exogenously given.

\subsection{Stability}

To consider the dynamical behavior of capital and stability issues, it is necessary to define a dynamic equilibrium and a steady-state equilibrium for the capital market. The dynamic equilibrium is given by Equation (13). To study this dynamic equilibrium it is appropriate to define a fixed point of capital per worker $\bar{k}$, where $\lim _{t \rightarrow+\infty} k_{t+1}=\bar{k}$, and assume that all other variables are constant. Accordingly, the population growth rate is constant.

Stability is scrutinized by conducting two simplifications, that subsequently are relaxed. The first simplification is to assume that the population growth rate is constant. The second is to exclude the government and thereby the public pension scheme.

Assumption 1 The population growth rate is assumed to be time-invariant, i.e.

$n_{t}=n \forall t \Rightarrow\left(N_{t}-N_{t-1}\right) / N_{t-1}=n=$ const .

Assumption 2 Governmental interventions are absent, i.e. $\tau=\Theta_{t}=0 \forall t$.

The rationale for this step-wise strategy is to present the necessary background for the following analysis. Assumptions 1 and 2 imply that the savings function is augmented to $s_{t}=\rho w_{t}$, as given in (6). The dynamics of capital per worker are thus given by:

$$
(1+n) k_{t+1}=\rho \beta k_{t}^{\alpha} .
$$

Equation (14) is a homogenous and nonlinear difference equation of the first order. To evaluate stability around a steady-state equilibrium it is useful to define the state transition function:

$$
k_{t+1}=\phi\left(k_{t}\right),
$$

where $\phi$ is a continuously differentiable function on $\mathbb{R}_{+}$. The steady-state equilibrium in this simplified framework is given by:

$$
\bar{k}=\left[\frac{\rho \beta}{1+n}\right]^{\frac{1}{1-\alpha}} .
$$

There are two steady-states. As $\phi(0)=0$ there exists a corner steady-state, which is unstable. The second steady-state is interior and follows as $\phi$ is concave, i.e. $\phi^{\prime \prime}(k)<0$. Whether this steady-state is stable or not depends on the value of $\mathrm{d} k_{t+1} / \mathrm{d} k_{t}$ evaluated at $k_{t}=\bar{k}$. Inspection of the derivative of Equation (14) yields that:

$$
\left.\frac{\mathrm{d} k_{t+1}}{\mathrm{~d} k_{t}}\right|_{k_{t}=\bar{k}}=\alpha
$$

Hence, as $\alpha \in(0,1)$, the trajectory $\left\{k_{t}\right\}_{t=0}^{\infty}$ is locally asymptotically stable converging monotonically to the steady-state level of capital per worker.

The next step in the stability analysis is to relax Assumption 1 and 2. The dynamic behavior of the capital intensity is then given by the first order, nonlinear difference Equation in (13). The state transition function is now given by:

$$
k_{t+1}=\Phi\left(k_{t}, n_{t+1}\right) \text {, }
$$

where $\Phi$ is a continuously differentiable function on $\mathbb{R}_{+}^{2}$. Steady-state equilibrium is within this set up given by a stationary capital-labor ratio characterized by the following implicit relation:

$$
(1+n) \bar{k}=\rho \beta \bar{k}^{\alpha}-\tau\left(\rho+\gamma \frac{1+n}{1+\alpha \bar{k}^{-\beta}}\right) .
$$


To study stability conditions of the interior steady-state, it is convenient to consider $d k_{t+1} / d k_{t}$, which becomes:

$$
\Phi_{k}^{\prime}:=\frac{\mathrm{d} k_{t+1}}{\mathrm{~d} k_{t}}=\frac{\alpha \beta \rho k_{t}^{-\beta}}{\left(1+n_{t+1}\right)\left[1+\alpha \beta \gamma \tau \psi\left(k_{t+1}\right)\right]},
$$

where

$$
\psi\left(k_{t+1}\right):=\frac{k_{t+1}^{-(1+\beta)}}{\left(1+\alpha k_{t+1}^{-\beta}\right)^{2}} .
$$

Evaluating Equation (19) demonstrates that:

$$
\lim _{k \rightarrow 0} \Phi_{k}^{\prime}=+\infty, \quad \lim _{k \rightarrow+\infty} \Phi_{k}^{\prime}=0,
$$

i.e. the steady-state, satisfying Equation (18), is unique and locally asymptotically stable.

\section{Population Ageing and Capital Accumulation}

A PAYGO social security imply that the capital market equilibrium given in Equation (13) must hold in every period. Inspection of this intertemporal equation reveals that capital intensity is affected by demographic changes in the economy. Endowed with perfect foresight with respect to demographic trends, each individual in the model economy is capable of internalizing future changes in the population in their consumption and saving decisions. Hence, if the population growth rate changes in period $t+1$, this is foreseen by the agents in the economy in period $t$, and accordingly accounted for. Population ageing, analyzed as a once-and-for-all drop in the fertility rate $n$, will therefore affect the capital stock and capital accumulation in the economy.

To study the consequences on the economy of population ageing it is convenient to reformulate capital intensity given in Equation (13) to:

$$
\chi\left(k_{t}, k_{t+1}, n_{t+1}\right):=k_{t+1}-\frac{\rho \beta k_{t}^{\alpha}}{1+n_{t+1}}+\frac{\rho \tau}{1+n_{t+1}}+\frac{\gamma \tau}{1+\alpha k_{t+1}^{-\beta}}=0,
$$

where $\chi$ is a continuously differentiable function on $\mathbb{R}_{+}^{3}$. Its partial derivatives is computed by using the implicit function theorem:

$$
\chi_{k_{t}}^{\prime} \mathrm{d} k_{t}+\chi_{k_{t+1}}^{\prime} \mathrm{d} k_{t+1}+\chi_{n_{t+1}}^{\prime} \mathrm{d} n_{t+1}=0
$$

In which

$$
\begin{gathered}
\chi_{k_{t}}^{\prime}=-\frac{\alpha \beta \rho k_{t}^{\alpha-1}}{1+n_{t+1}}<0, \\
\chi_{k_{t+1}}^{\prime}=1+\frac{\alpha \beta \gamma \tau k_{t+1}^{-(1+\beta)}}{\left(1+\alpha k_{t+1}^{-\beta}\right)^{2}}>0, \\
\chi_{n_{t+1}}^{\prime}=\frac{\rho\left(\beta k_{t}^{\alpha}-\tau\right)}{\left(1+n_{t+1}\right)^{2}} .
\end{gathered}
$$

In the analysis of $\mathrm{d} k_{t+1} / \mathrm{d} n_{t+1}$, it is assumed that $\mathrm{d} k_{t}=0$. Accordingly, the following results are partial. Equation (20) now becomes:

$$
\chi_{k_{t+1}}^{\prime} \mathrm{d} k_{t+1}+\chi_{n_{t+1}}^{\prime} \mathrm{d} n_{t+1}=0
$$

and one can state the following proposition:

Proposition 1 A permanent increase in the elderly dependency ratio gives rise to the long-run capital stock, i.e. $\mathrm{d} k / \mathrm{d} n<0$. 
Proof. The proposition is proved by contradiction. Inserting for $\chi_{k_{t+1}}^{\prime}$ and $\chi_{n_{t+1}}^{\prime}$ from (20) into Equation (21), gives the following relation between the population growth rate and the stock of capital in the economy:

$$
\frac{\mathrm{d} k_{t+1}}{\mathrm{~d} n_{t+1}}=-\frac{\chi_{n_{t+1}}^{\prime}}{\chi_{k_{t+1}}^{\prime}}=-\frac{\rho\left(\beta k_{t}^{\alpha}-\tau\right)\left(1+\alpha k_{t+1}^{-\beta}\right)^{2}}{\left(1+n_{t+1}\right)^{2}\left[\left(1+\alpha k_{t+1}^{-\beta}\right)^{2}+\alpha \beta \gamma \tau k_{t+1}^{-(1+\beta)}\right]} .
$$

Inspection of the above expression reveals that the denominator is unambiguously positive. Since the proof is showed by contradiction, it is assumed that $\mathrm{d} k_{t+1} / \mathrm{d} n_{t+1}>0$, which requires that the sign on the numerator is negative, and subsequently that:

$$
\beta k_{t}^{\alpha}<\tau .
$$

But, as the LHS equals the wage ${ }^{2}$, and the wage obviously must be higher than the lump-sum tax, the above inequality yields a contradiction. Therefore one has that:

$$
\forall t \quad \beta k_{t}^{\alpha}>\tau \Rightarrow \frac{\mathrm{d} k_{t+1}}{\mathrm{~d} n_{t+1}}<0 .
$$

Hence, population ageing increase the long-run capital intensity. QED

The result reflects that old individuals, who own assets due to earlier saving, are becoming a larger proportion of the population, while the proportion of young individuals, who own no assets, are becoming less. Subsequently, saving increases and boosts capital accumulation. Moreover, the transition path is characterized by a gradual increase in the wage rate and a fall in the interest rate. This is seen by differentiating the first order conditions in (8) and (9), while exploiting the relation in (1) and the definition in (7):

$$
\frac{\mathrm{d} w_{t}}{\mathrm{~d} n_{t}}=-\frac{\alpha \beta k_{t}^{\alpha}}{1+n_{t}}<0 \quad \text { and } \quad \frac{\mathrm{d} r_{t}}{\mathrm{~d} n_{t}}=\frac{\alpha \beta}{\left(1+n_{t}\right) k_{t}^{\beta}}>0,
$$
dels.

These qualitative results correspond well to the results given by several more detailed and complicated mo-

\section{Conclusions}

This paper is motivated by the ongoing debate regarding the consequences of population ageing. Since several countries rely on PAYGO pension systems, the current paper investigates how ageing affects capital accumulation with such a pension scheme. Thus, a standard OLG model is extended with a PAYGO pension system, and an exogenous variable for the population growth rate. In order to achieve explicit solutions, specific functional forms has been chosen on production and utility behavior.

The main result in the paper is interesting. It is shown that an increase in the elderly dependency ratio will increase the long-run capital stock. Thus, although the demographic transition along the PAYGO scheme may cause a financial challenge for the governmental budgets, capital accumulation will increase. This may stimulate economic growth led by physical capital accumulation. As far as such a pattern increase income in the society, this may cause an indirect improvement in the governments budgets. Thus, we can have two effects on the financial budgets working in opposite directions. To scrutinize such effects is a natural extension of the current paper.

The contribution of the current paper is accordingly threefold. Firstly, the formulation allows explicit solutions for the impact of population ageing on capital accumulation. Secondly, it is shown that population ageing will increase the capital stock. Thirdly, the formulation opens up for different extensions to shed light on several aspects of pension economics. It is also important to note that the simplified formulation limits the possibility of country-specific studies of the details in the social security systems. To conduct such studies require large-scale models that needs to be solved numerically.

\section{Acknowledgements}

I would like to thank Steinar Holden, Øystein Thøgersen, Hans Fehr, participants at the 2015 FIBE conference

\footnotetext{
${ }^{2}$ See the first order condition given in (9).
} 
in Bergen, Norway, and an anonymous referee for helpful comments.

\section{References}

[1] Börsch-Supan, A., Ludwig, A. and Winter, J. (2006) Ageing, Pension Reform and Capital Flows: A Multicountry Simulation Model. Economica, 73, 625-658.

[2] United Nations Population Division (2012) World Population Prospects: The 2011 Revision. United Nations.

[3] Cutler, D.M., Poterba, J.M., Sheiner, L.M. and Summers, L.H. (1999) An Aging Society: Opportunity or Challenge? Brookings Papers on Economic Activity, 1, 1-56.

[4] Sadahiro, A. and Shimasawa, M. (2004) Ageing, Policy Reforms and International Capital Flows in a Computable TwoCountry OLG Model. ESRI Discussion Paper Series No. 97.

[5] Attanasio, O. and Violante, G. (2000) The Demographic Transition in Closed and Open Economies: A Tale of Two Regions. Inter-American Development Bank Working Papers 412.

[6] Auerbach, A. and Kotlikoff, L. (1987) Dynamic Fiscal Policy. Cambridge University Press, Cambridge.

[7] Meijdam, L. and Verbon, H.A.A. (1997) Aging and Public Pensions in an Overlapping-Generations Model. Oxford Economic Papers, 49, 29-42. http://dx.doi.org/10.1093/oxfordjournals.oep.a028595

[8] Marchand, M., Michel, P. and Pestieau, P. (1996) Intergenerational Transfers in an Endogenous Growth Model with Fertility Changes. European Journal of Political Economy, 12, 33-48. http://dx.doi.org/10.1016/0176-2680(95)00036-4

[9] Diamond, P.A. (1965) National Debt in a Neoclassical Growth Model. American Economic Review, 55, 1126-1150. 